\title{
Effect of amygdaloid lesions on avoidance learning in the rat'
}

Rats with bilateral lesions in the basolateral amygdaloid nuclei were taught to press a lever to avoid electric shock. The difficulty of the avoidance task was manipulated by using an auditory or visual cue to signal the preshock period during which an avoidance response could be made. Amygdaloid lesions had no effect, either disruptive or facilitative on either the easy or difficult task. The effect of septal lesions on the acquisition of easy and difficult avoidance tasks obtained by other investigators is compared with the results obtained in the present experiment.

Permanent alterations in affective behavior associated with damage to the amygdaloid nuclei have been found in cat (Horvath, 1963), rat (Robinson, 1963), and monkey (Weiskrantz, 1956 ). Loss of fear motivated responses is one of the most commonly reported changes following injury to these nuclei. As would be predicted by the hypothesis that avoidance learning is dependent on fear reduction (Miller, 1951) amygdalectomy has been found to impair the acquisition of an active avoidance response. However, while there is ample evidence that damage of the amygdaloid complex in primates or carnivores interferes with avoidance learning (Schreiner \& Kling, 1953; Horvath, 1963; Gloor, 1960) results obtained with rats are less conclusive. Kling (1958) could find no effect of amygdaloid lesions on rate of acquisition in a shuttle box. More recently, Robinson (1963) reported similar negative findings using a Miller shock-escape box. On the other hand, Kellicutt \& Schwartzbaum (1963) report marked impairment in the formation of a conditioned emotional response following amygdaloid lesions.

Possible reasons for these different findings could include species differences (Nakamura, 1962), transient or delayed changes in the lesioned area and differential destruction of various subnuclei (Ursin \& Kaada, 1960). Another possibility which may account for the results mentioned above is that given changes in fear may have differential effects upon the acquisition of an avoidance response depending upon task difficulty. For example, it has been shown that septal lesions which have been hypothesized to reduce fear (Kenyon, 1965) enhance acquisition of a two way (difficult) conditioned avoidance response but retard acquisition of a one way (easy) conditioned avoidance response.

In order to test for the possibility that amygdaloid lesions have similar differential effects upon acquisition of a "difficult" as opposed to an "easy" avoidance response, a visual or an auditory cue was used as contioned stimuli in the present experiment. The results of a previous study with normal rats showed that it is much more difficult for a rat to learn a bar press avoidance response when a visual stimulus is used as a conditioned stimulus than when an auditory one is used (D'Amato, Keller, \& DiCara, 1964).

Subjects

Ss were 16 experimentally naive albino rats of the Sprague-Dawley strain weighing approximately $375 \mathrm{gm}$. Eight of the rats were amygdalectomized and the remaining eight were sham operated. Within each of these two groups, half of the rats were trained with an auditory and the other half with a visual stimulus.

\section{Surgery and Histology}

Electrolytic destruction of the amygdaloid nuclei was performed under Nembutal and Chloral Hydrate anesthesia. Two small holes, one over each hemisphere, were made in the exposed skull using a dental drill. The electrolytic lesions were made stereotaxically using a $2 \mathrm{ma}$ direct current for $20 \mathrm{sec}$. The sham operated controls underwent the identical procedure except for the passage of current. Ss were allowed a three week post-operative recovery period. At the completion of testing each rat was perfused with physiological saline and $10 \%$ formalin. The brain was then removed, fixed in formalin for one week and then sections cut at 40 microns and stained with cresyl violet.

\section{Procedure and Apparatus}

A commercial Skinner box was used. The auditory stimulus, a $1000 \mathrm{cps}$ tone at $84 \mathrm{db}$ was fed through a small speaker while the visual stimulus consisted of an increase in illumination provided by a 60 watt bulb in the experimental chamber. Ss were kept in semi-darkness between trials. Each trial consisted of a $5 \mathrm{sec}$. presentation of the CS, either sound or light, followed by the UCS (a continuous electric shock of 1 ma intensity delivered through a grid scrambling device) and CS uitil $S$ pressed the lever. If $\mathrm{S}$ pressed the lever during the $5 \mathrm{sec}$. CS presentation period the shock was not given. If $S$ did not press the lever during the 5 sec. CS presentation period, the CS stayed on until the animal made a response. On the first day of training $S$ was shaped to make an escape response. The following day $S$ received 500 consecutive trials. The trials were spaced by a film tape programmer with a mean intertrial interval of 30 sec. and upper and lower limits of 90 and $15 \mathrm{sec}$. All data (number of escape and avoidances) was recorded automatically. 
Table 1. Percentage of avoidance responses made by individual anygdalectomized and control Ss given an auditory or a visual CS.

\begin{tabular}{lcc} 
& Amygdalectomized & Control \\
\hline Auditory & 9.9 & 12.8 \\
& 17.6 & 22.5 \\
& 21.4 & 27.0 \\
& 39.3 & 34.7 \\
\hline Visual & 0.0 & 0.0 \\
& 0.6 & 0.1 \\
& 3.2 & 1.5 \\
& 7.1 & 2.7 \\
\hline
\end{tabular}

\section{Results}

The mean percentage of avoidance responses for each $S$ in the lesion and control groups under visual and auditory CS conditions are presented in Table 1.

It is clear that in both lesion and control groups the $1000 \mathrm{cps}$ tone was a more efficient CS than was the increase in illumination. An analysis of variance showed that these differences were significant at the .001 level $(F=18.6)$; however, within a particular CS condition there was no difference between lesion and control Ss in their ability to learn the avoidance response $(F=.26)$. Interaction between $C S$ sense modality and lesion versus control groups was also significant $(F=.37)$.

Microscopic examination of the lesions revealed complete destruction to the basolateral nuclei in all lesioned Ss. Some Ss sustained damage to the globus pallidus and fringe of the internal capsule.

\section{Discussion}

The CS manipulation used to vary the difficulty of the avoidance task was successful. Both the lesion and control groups given the auditory CS made significantly more avoidance responses than the corresponding groups given the visual CS. On the other hand, amygdaloid lesions had no effect, either disruptive or facilitative on either the "difficult" or "easy" avoidance tasks. This finding is in contrast to what has been reported by Kenyon \& Krieckhaus (1965) in septal animals performing easy or difficult shuttle box avoidance. Since it has been suggested that both septal (Kenyon \& Krieckhaus, 1965) and amygdaloid lesions (Gloor, 1960) reduce fear one might have expected to find that amygdaloid lesions would have different effects on the acquisition of an avoidance response depending upon task difficulty.

\section{References}

D'Amato, M. R., Keller, D., \& DiCara, L. Facilitation of dis criminated avoidance learning by discontinuous sheck. $J$. comp. physiol. Psuchol., 1964, 58, 344-349.

Gloor, P. Amygdala. In J. Field (Ed.), Handbook of phy siolooy. Vol. 2, Washington, D. C.: Amer. Physiol. Soc. 1960. Pp. 13951420 .

Horvath, F. E. Effects of basolateral amygdalectomy on three types of avoidance behavior in cats. J. comp. physiol. Psuchol., 1963, 56, 380-389.

Kellicutt, H. M., \& Schwartzbaum. S. J. Formation of a conditioned avoidance response following lesions of the amygdaloid complex in rats. Psychol. Rep., 1963, 12, 351-358.

Kenyon, J., \& Kriekhaus, E. E. Decrements in one-way avoidance learning following septal lesions in rats. Psychon. Sci., 1965 $3,113-114$

King, F. A. Effects of septal and amygdaloid lesions on emotional behavior and conditioned avoidance responses in the rat. $J$. nerv. ment. Dis., 1958, 126, 57-63.

Miller, N. E. Learnable drivers and rewards. In S. S. Stevens (Ed.) Handbook of experimental psychology. New York: Wiley, 1951. Pp. 435-472.

Nakamura, C. Y., \& Anderson, N. Avoidance behavior differences within and between strains of rats. J. comp. physiol. Psychol., $1962,55,740-747$.

Robinson, E. Effect of amygdalectomy on fear motivated behavior in rats. J. comp. physiol. Psychol., 1963, 56, 814-820.

Schriner, L., \& Kling, A. Behavioral changes following rhinencephalic injury in the cat. $J$. Neurophysiol., 1953, 16, 643-659.

Ursin, H. \& Kaada, B. R. Functional localization within the amygdaloid complex in the cat. EEG clin. Neurophysiol., 1960, 12 , $1-20$.

Weiskrantz, L. Behavioral changes with ablation of the amygdaloid complex in monkey. J. comp. physiol. Psychol., 1956, 49, 381391 .

\section{Note}

1. This research was supported in part by research grant $\mathrm{MH} 00647$ to N. E. Miller and NSF Postdoctoral Fellowship 45078 to the author. 